\title{
Design of a Two-Element Antenna Array Using Substrate Integrated Waveguide Technique
}

\author{
Kheireddine Sellal ${ }^{1}$ and Larbi Talbi ${ }^{2}$ \\ ${ }^{1}$ Faculty of Engineering Phase 2, University of Moncton, Moncton Campus, 18 Antonine-Maillet Avenue Moncton, \\ NB, Canada E1A $3 E 9$ \\ ${ }^{2}$ Department of Computer Science and Engineering, University of Quebec in Outaouais (UQO), 101 Saint-Jean-Bosco, P.O. Box 1205, \\ Hull Station, Gatineau, QC, Canada J8Y $3 G 5$
}

Correspondence should be addressed to Kheireddine Sellal, kheireddine.sellal@umoncton.ca

Received 1 May 2011; Revised 1 July 2011; Accepted 1 July 2011

Academic Editor: Chien-Jen Wang

Copyright (๑) 2011 K. Sellal and L. Talbi. This is an open access article distributed under the Creative Commons Attribution License, which permits unrestricted use, distribution, and reproduction in any medium, provided the original work is properly cited.

\begin{abstract}
The design of a two-element antenna array using the substrate integrated waveguide (SIW) technique and operating at $10 \mathrm{GHz}$ is presented. The proposed antenna array consists of two SIW phase shifter sections with two SIW slot antennas. The phase shifting is achieved by changing the position of two inductive posts inserted inside each element of the array. Numerical simulations and experimental measurements have been carried out for three differential phases between the two antenna array elements, namely, $0^{\circ}, 22.5^{\circ}$, and $67.5^{\circ}$. A prototype for each differential phase has been fabricated and measured. Results have shown a fairly good agreement between theory and experiments. In fact, a reflection coefficient of better than $20 \mathrm{~dB}$ has been achieved around $10 \mathrm{GHZ}$. The E-plane radiation pattern has shown a beam scan between $5^{\circ}$ and $18^{\circ}$ and demonstrated the feasibility of designing an SIW antenna phased array.
\end{abstract}

\section{Introduction}

The radiation patterns of many antennas such as the dipole, loop, and microstrip patch have a fairly wide beam width (low gain), making them suitable candidates for applications requiring a broad coverage area. In many applications, however, there is a need for a more focused radiation patterns (high gain), such as in point-to-point terrestrial links, satellite communications, and air-traffic radar. A more focused radiation pattern will also extend the communication range [1]. To create a more directive radiation pattern, the size of the antenna must be increased. This can be done with simple resonant antennas like the dipole and the loop, but it is usually difficult to control the side lobe levels of these antennas. Traveling-wave antennas (helical antenna, etc.) can produce higher directivity by increasing the length and number of turns of the helix. Moderate gains (10-15 dB) can be achieved by long helical antennas, but they cannot achieve very high gains, due to the impractical length required. Another antenna which can produce relatively high gain is the waveguide horn, which is an extension of an open waveguide with flared walls at the open end. Waveguide horns are particularly useful at higher frequencies $(>5 \mathrm{GHz})$ where their size and weight become manageable [1]. Some aspects of the radiation pattern can be controlled by designing horns with the proper flare angle and length or by adding corrugations to the inner walls. Another choice for achieving higher gain is to use a reflector (parabolic dish, etc.) to focus the energy of a low gain antenna. Reflector antennas offer very good electrical performance, but require careful mechanical design to ensure that the reflector surface is properly shaped and that the feed is properly located at the focal point. The feed antenna must also be properly designed to optimize the performance of the reflector [1].

An alternative to the above approaches is to use an array of simple antennas which are linked together to operate as a single antenna. The number of antenna elements, their special location, their relative amplitudes, and phases are all design parameters which can be used to shape the radiation pattern of the overall array. Arrays are therefore very versatile, 


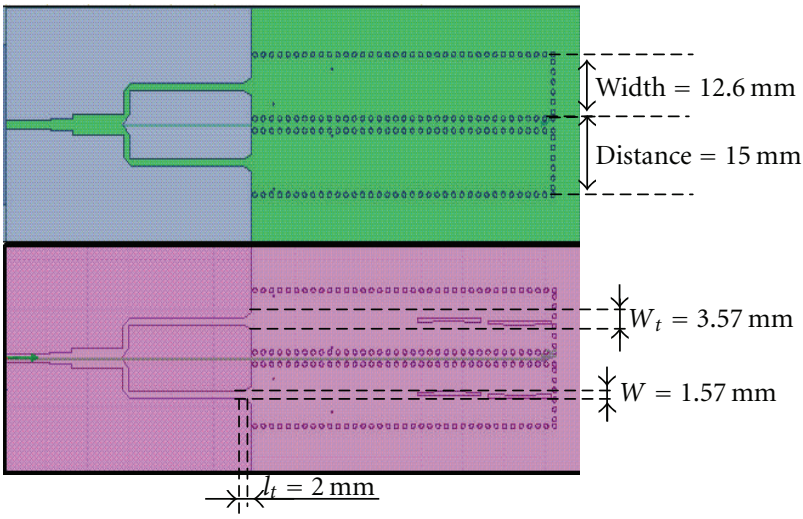

(a)

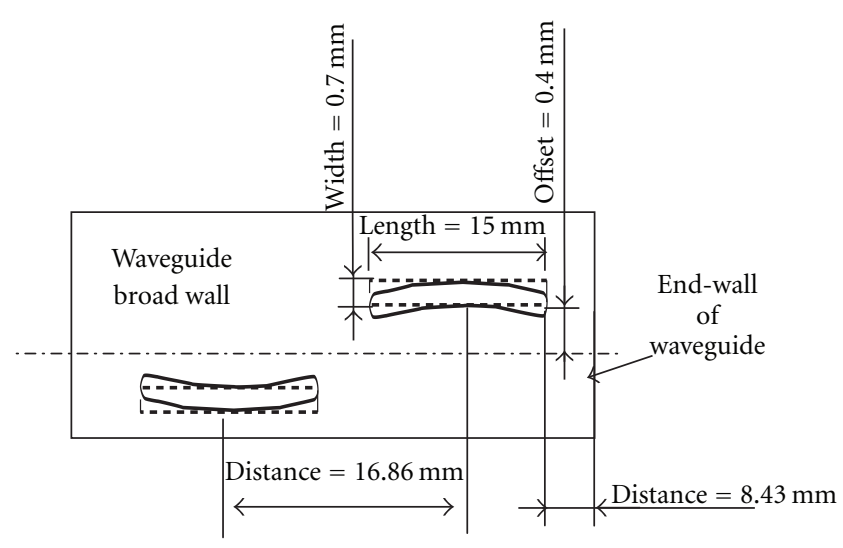

(b)

FIGURE 1: Structure of the two-element antenna array: (a) simulation model; (b) details of the round-ended banana-shaped slots.

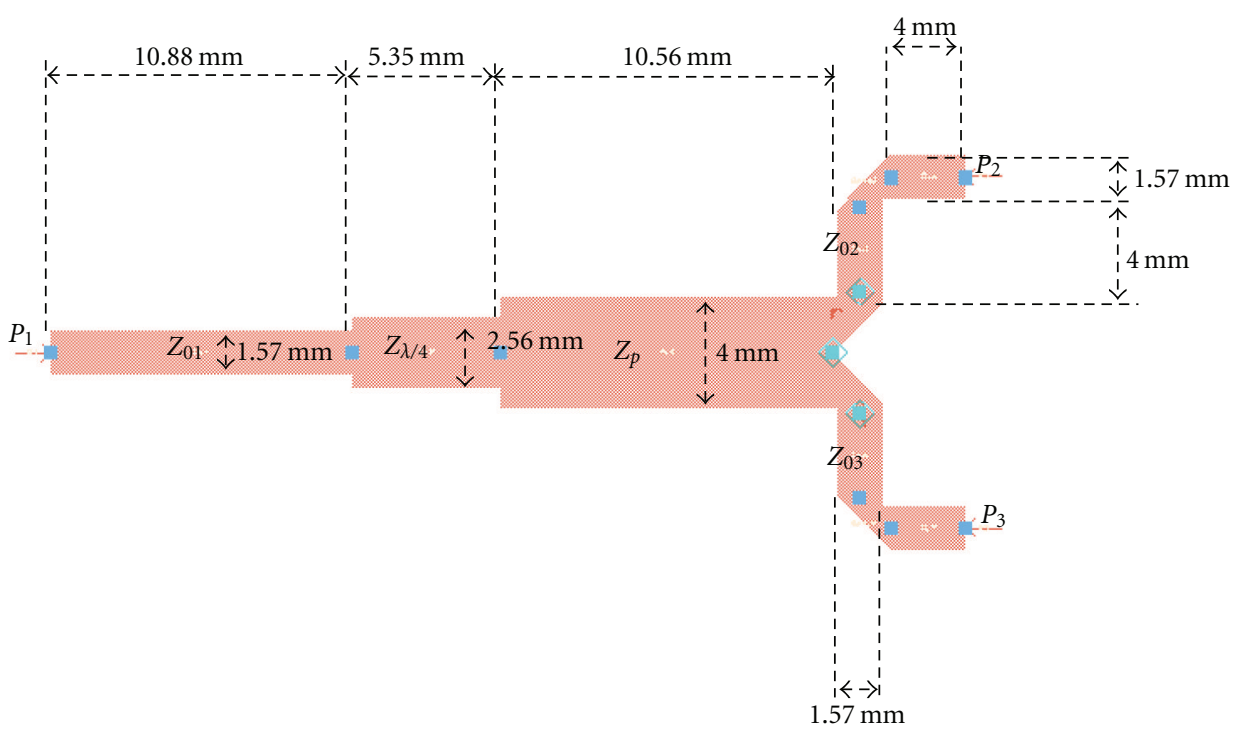

FIgURe 2: Antenna array's feed network.

since the designer can control numerous aspects of the radiation pattern including the location of the beam peak, the maximum side lobe levels, and the location of the nulls. Furthermore, by integrating electronic phase shifters into the array, dynamic control of the radiation pattern is possible, allowing for steering of the main beam or of nulls [1].

In the last years, the concept of the substrate integrated waveguide (SIW) has been proposed [2], in which an "artificial" waveguide is synthesized and constructed with linear arrays of metalized via holes or posts embedded in the same substrate. The connection between the waveguide and the planar circuits is provided via transitions formed with a simple matching geometry between both structures $[3,4]$, thus providing a compact and low-cost platform. This new SIW concept allowed for the design of microwave and millimeter-wave circuits such as antennas and antenna arrays. In fact, in 2004, Farrall and Young [5] have presented an SIW slot antenna operating at $10 \mathrm{GHz}$, where they have fabricated a one- and two-slot antennas. $S 11$ about $-28 \mathrm{~dB}$ has been achieved in both cases, and a gain $3 \mathrm{~dB}$ higher for the two-slot antenna has been obtained. The same year, Yan et al. [6] have designed and fabricated an SIW antenna with an array of slots. $S 11$ of $-18 \mathrm{~dB}$ has been obtained around 10.2 GHz. A measured gain of $15.7 \mathrm{~dB}$ was achieved. Then in 2005, a couple of SIW slot antennas have been presented in [7-10] by Young et al. In the first work [7], an SIW slot antenna using thick photo-imageable film technology on a reduced thickness substrate has been realized. The antenna operated at $\mathrm{W}$-band where the resonance frequency was $96.4 \mathrm{GHz}$ with a return loss around $-20 \mathrm{~dB}$. In [8], the authors have presented a slot antenna using a folded SIW, reducing the width of the original guide by half. Simulations have shown a $-18 \mathrm{~dB}$ return loss and a $400 \mathrm{MHz}$ bandwidth with a $6.5 \mathrm{~dB}$ gain. The same authors have presented two other slot antennas using three main components: a nonradiating SMA-waveguide transition, a power divider from the standard waveguide to the folded waveguide, and an array of slots on the folded one. In [9], the measurement data 


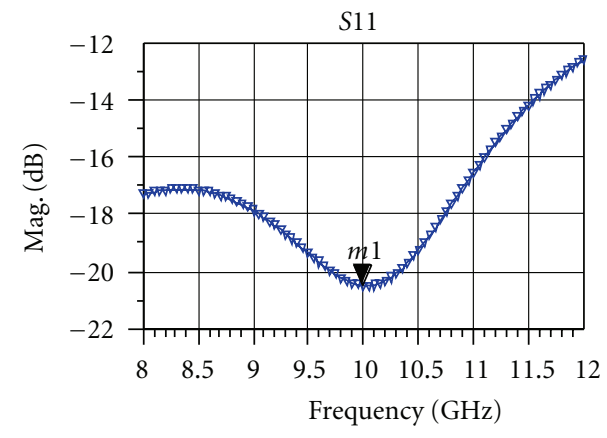

$m 1$

Freq $=10 \mathrm{GHz}$

$\mathrm{dB}($ alimentation_SIW_slotted_array_antennal_mom. . $S(1,1))=-20.521$
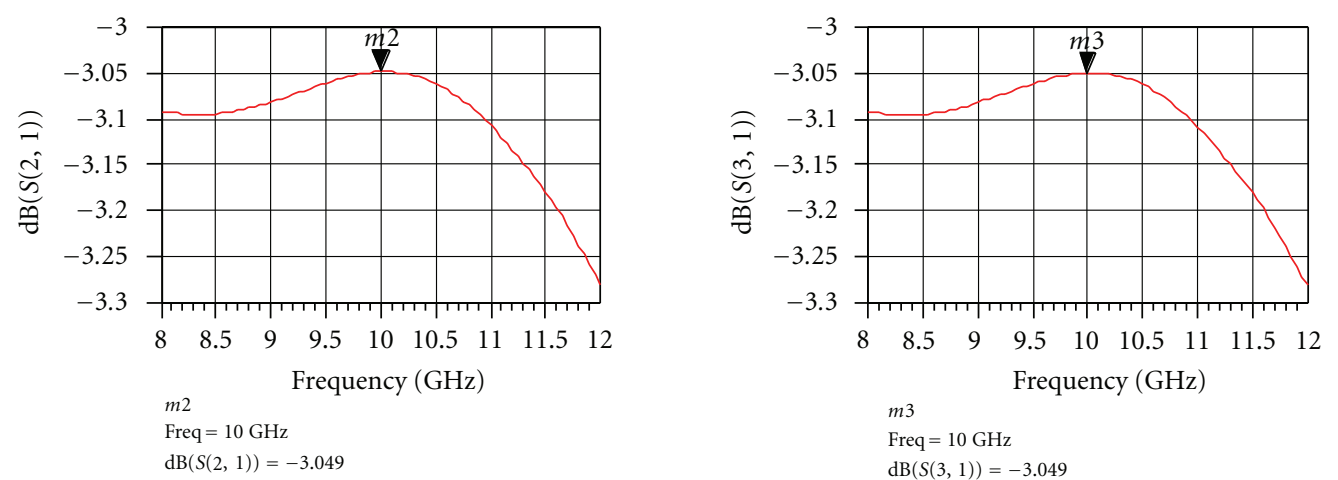

$m 3$

Freq $=10 \mathrm{GHz}$

$\mathrm{dB}(S(3,1))=-3.049$
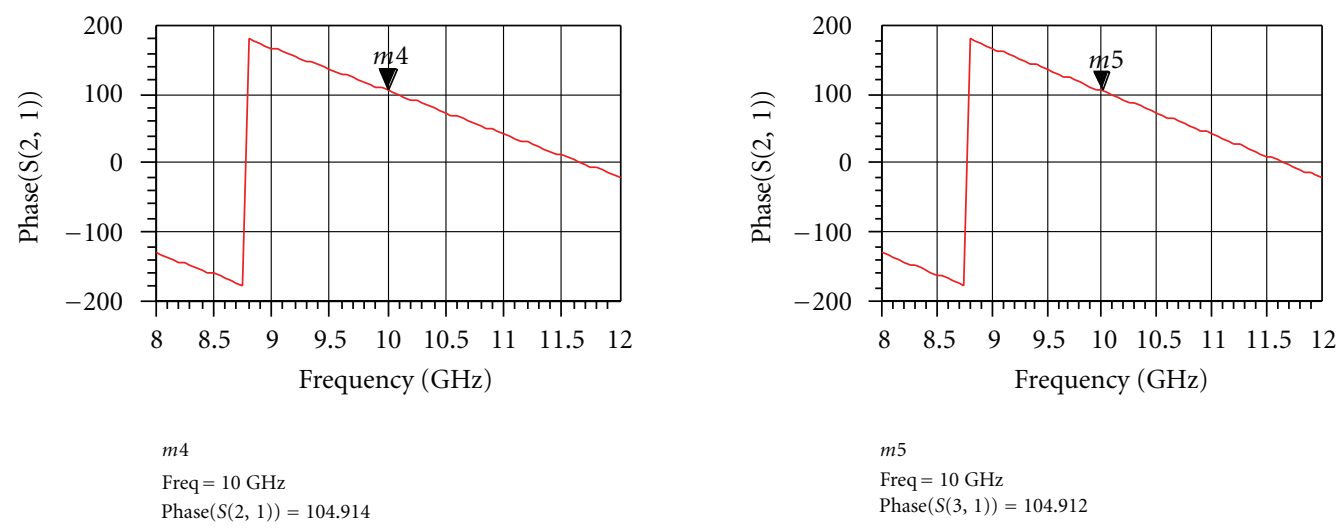

$m 5$

Freq $=10 \mathrm{GHz}$

$\operatorname{Phase}(S(3,1))=104.912$

FIgURE 3: Simulation results of the antenna array's feed network.

indicated a $-24.4 \mathrm{~dB}$ reflection coefficient, a bandwidth of $255 \mathrm{MHz}$, around a resonance frequency of $9.53 \mathrm{GHz}$, and an $8 \mathrm{~dB}$ gain for the two-slot design and a $6.5 \mathrm{~dB}$ for the one-slot design. While in [10], a reflection coefficient of $-19.7 \mathrm{~dB}$, a $525 \mathrm{MHz}$ bandwidth, around $8.96 \mathrm{GHz}$, have been achieved. Yan et al. [11] have developed a monopulse antenna using $4 \times 8$ longitudinal slots and operating at $10 \mathrm{GHz}$. In 2006, Weng et al. [12], have studied a slot antenna in the Ku-Band and have obtained a reflection coefficient less than $-10 \mathrm{~dB}$ on a $500 \mathrm{MHz}$ frequency bandwidth. Hong et al., have presented their activity at State Key Lab, concerning various antennas as slot-array, leaky-wave, omnidirectional, monopulse, and dielectric resonator antennas, filtennas and rectennas [13].
As a contribution to SIW technology, this paper discusses the feasibility of an SIW antenna array. To do so, a twoelement antenna array was fabricated and measured.

\section{Structure of the Two-Element Antenna Array}

In the light of the theory of antenna array design [1, 14], the proposed two-element antenna array combines the SIW phase shifter presented in [15] and an SIW slot antenna presented in [16]. The proposed structure is shown in Figure 1. In the SIW, the vertical walls of a rectangular waveguide (RWG) are replaced by a series of metal posts known as vias. Drilling holes in the substrate and then plating 


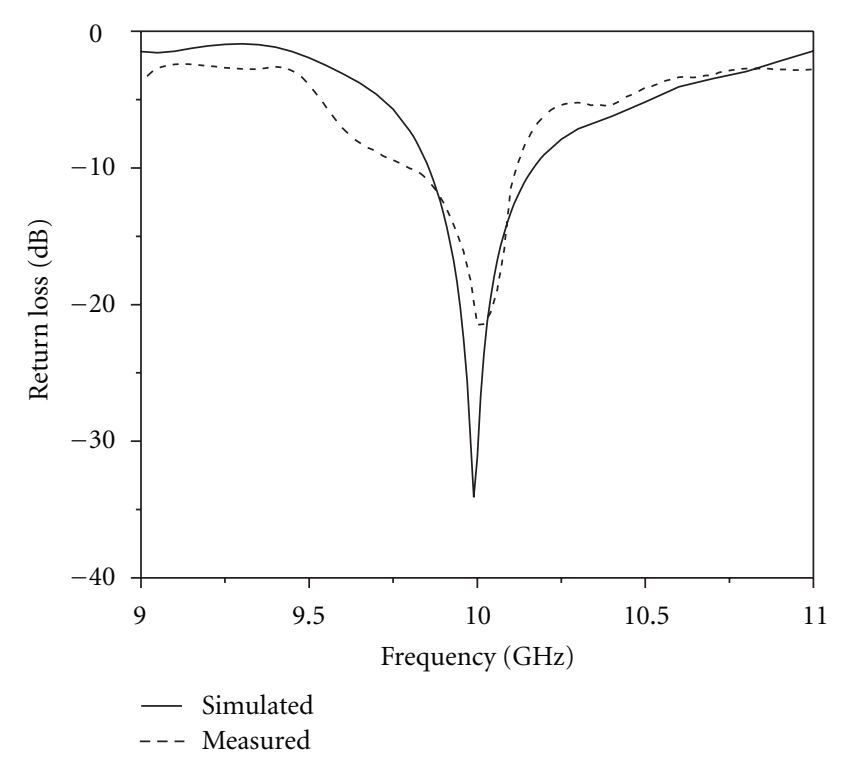

FIGURE 4: Simulated and measured reflection coefficients for $0^{\circ}$ phase progression.

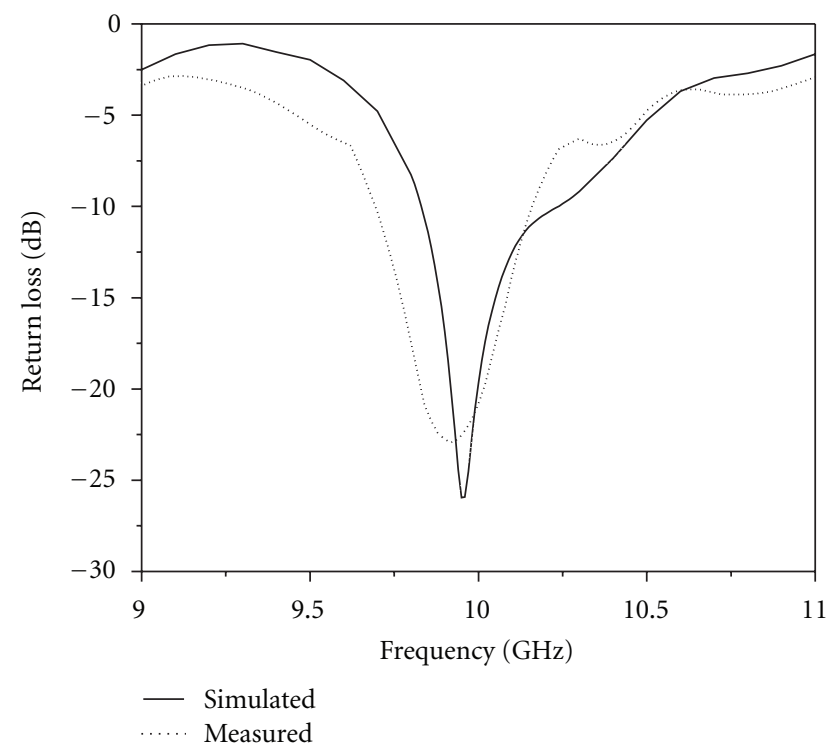

FIGURE 5: Simulated and measured reflection coefficients for $22.5^{\circ}$ phase progression.

them with metal forms these vias. The bottom and top of the RWG are formed with metal cladding on the substrate. The two vias located inside the synthesized waveguide will be used to alter the phase of the incident wave by changing their position in the substrate. The SIW slot antenna uses bananashaped slots whose results are given in [16].

\section{Design, Simulations, and Experimental Results}

The SIW waveguide was designed applying the rules given in [2]. The antenna array was designed using the theory

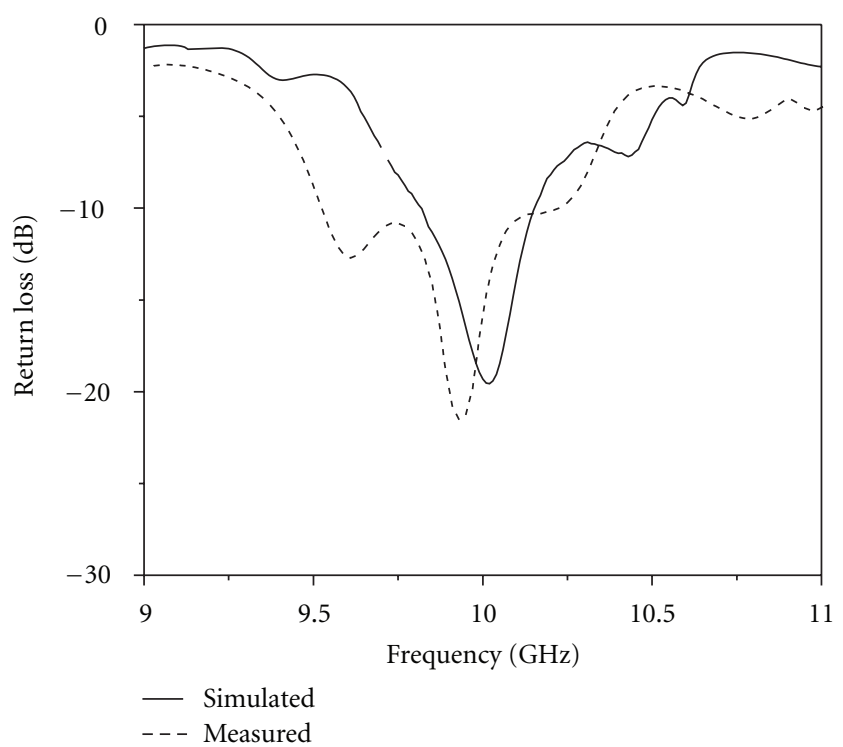

FIGURE 6: Simulated and measured reflection coefficients for $67.5^{\circ}$ phase progression.

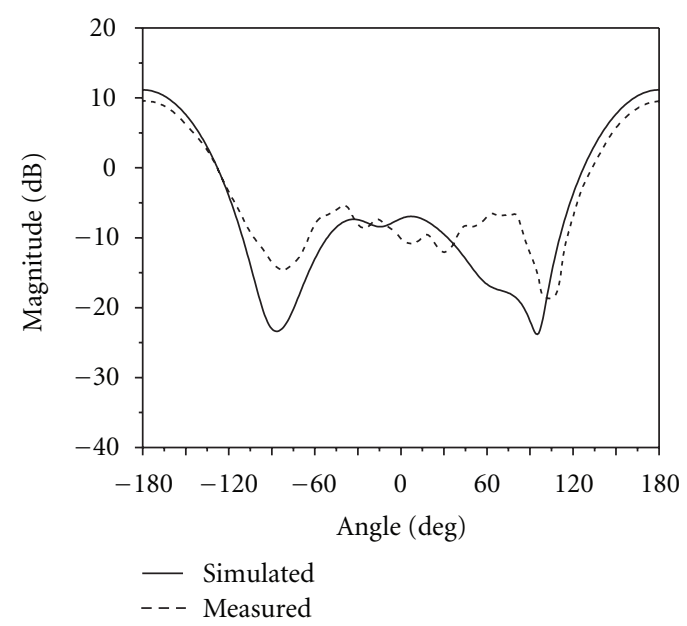

FIGURE 7: Simulated and measured E-plane radiation patterns reflection coefficients for $0^{\circ}$ phase progression.

presented in $[1,14]$. The distance between the two elements of the array has been chosen to be $\lambda / 2$.

To design the antenna array operating at $10 \mathrm{GHz}$, we used ROGERS RT/Duroid 5880 substrate, with a relative permittivity $\varepsilon_{r}=2.2$ and thickness $b=0.512 \mathrm{~mm}$. This gives a waveguide width of $12.6 \mathrm{~mm}$ for X-band operation. The synthesized metallic side walls of the SIW waveguide are represented by an array of metallised vias of diameter $1 \mathrm{~mm}$ with a $2 \mathrm{~mm}$ pitch. The parameters of the microstrip to SIW transition were as follows: $l_{t}=2 \mathrm{~mm}, W=1.57 \mathrm{~mm}$, and $W_{t}=3.57 \mathrm{~mm}$. The slots were placed $16.86 \mathrm{~mm}$ apart, and the distance from the end of the waveguide to the last slot was set to $8.43 \mathrm{~mm}$. The width of the slots was $0.7 \mathrm{~mm}$, the offset was $0.4 \mathrm{~mm}$, and the length was $15 \mathrm{~mm}$. 


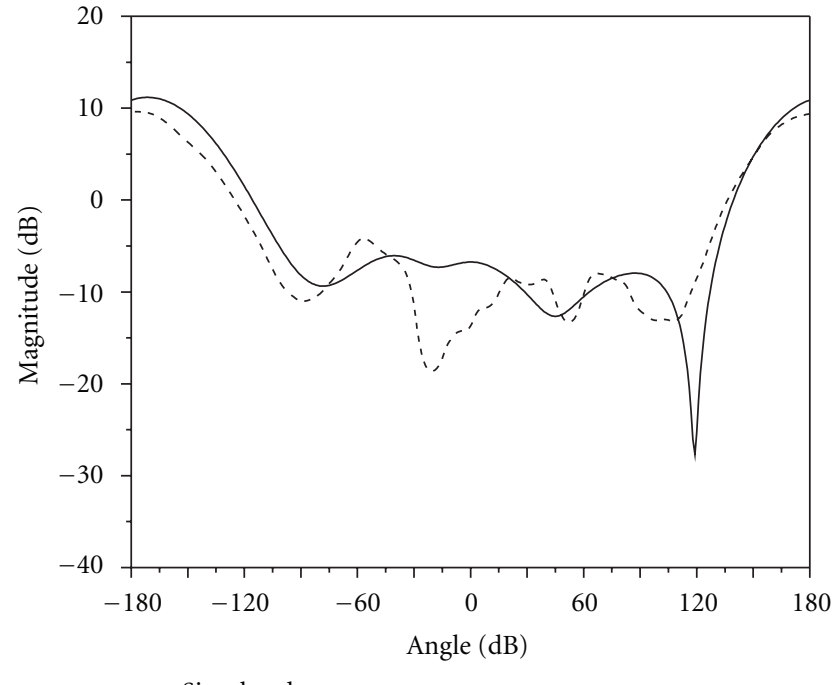

- Simulated

- - - Measured

FIGURE 8: Simulated and measured E-plane radiation patterns reflection coefficients for $22.5^{\circ}$ phase progression.

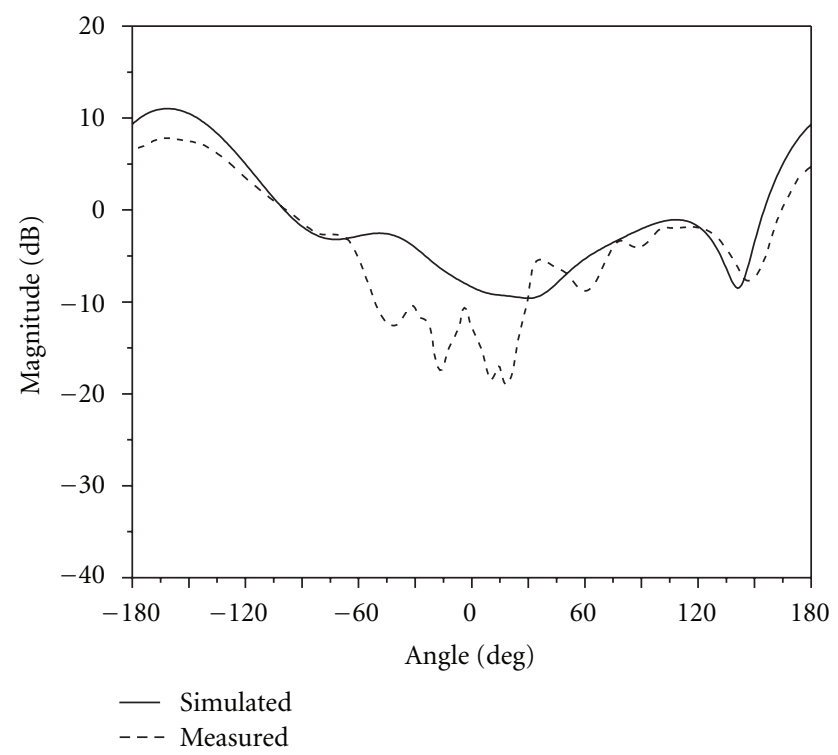

FIGURE 9: Simulated and measured E-plane radiation patterns reflection coefficients for $67.5^{\circ}$ phase progression.

To measure the two-element antenna array, we had to design the power divider represented in Figure 2. We have calculated the different impedances as follows [5]:

$$
P_{2}=P_{3}=\frac{P_{1}}{2} \text {. }
$$

We considered

$$
\begin{aligned}
& Z_{01}=Z_{02}=Z_{03}=50 \Omega \\
& Z_{P}=\frac{Z_{02} Z_{03}}{Z_{02}+Z_{03}}=25 \Omega .
\end{aligned}
$$

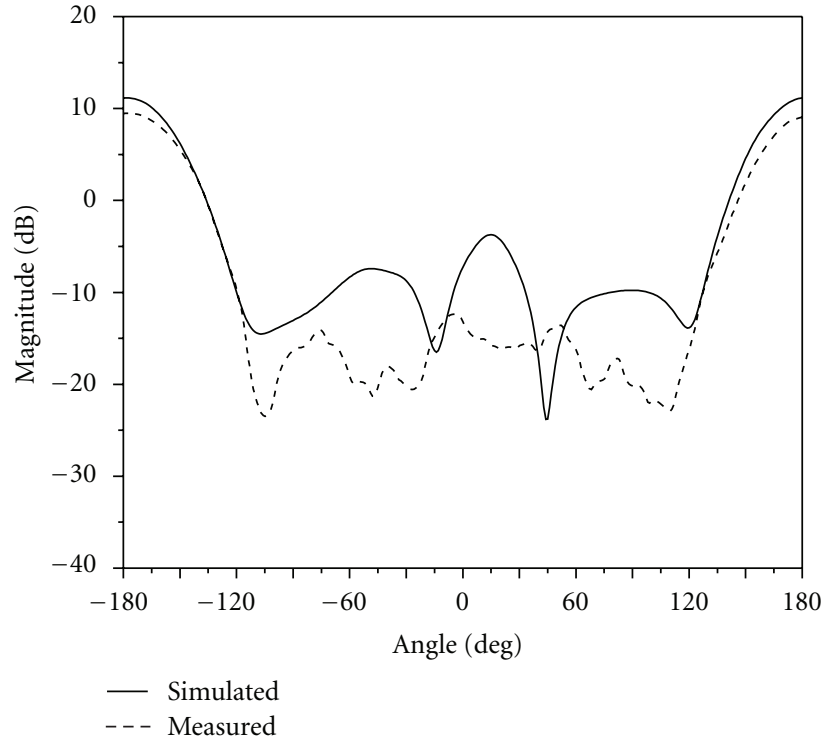

Figure 10: Simulated and measured $H$-plane radiation patterns reflection coefficients for $0^{\circ}$ phase progression.

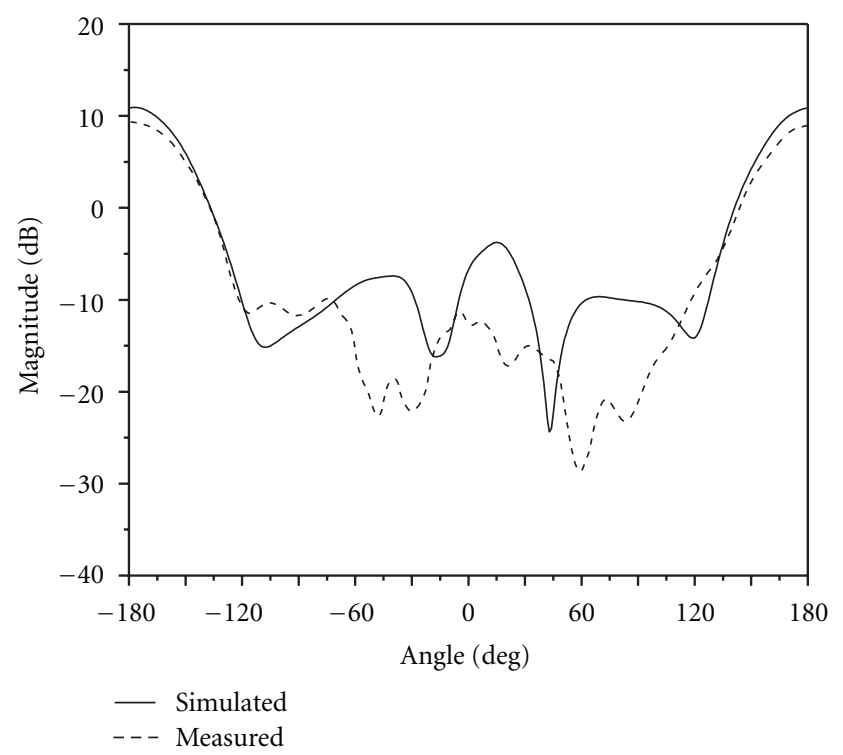

FIGURE 11: Simulated and measured $H$-plane radiation patterns reflection coefficients for $22.5^{\circ}$ phase progression.

To match the input microstrip to the microstrip of impedance $Z_{p}$, we used a quarter wavelength line of impedance:

$$
Z_{\lambda / 4}=\sqrt{Z_{01} Z_{P}}=35.35 \Omega
$$

LineCalc of Agilent allowed us to determine the widths and the lengths of the different microstrip lines. The simulation results regarding the feed network are represented in Figure 3. $S 11$ is around $-20.5 \mathrm{~dB}$ at $10 \mathrm{GHz}$; $S 21$ and $S 31$ were $-3.012 \mathrm{~dB}$ and $-3.049 \mathrm{~dB}$, respectively, corresponding to insertion losses of $0.012 \mathrm{~dB}$ and $0.049 \mathrm{~dB}$, for the two branches. 


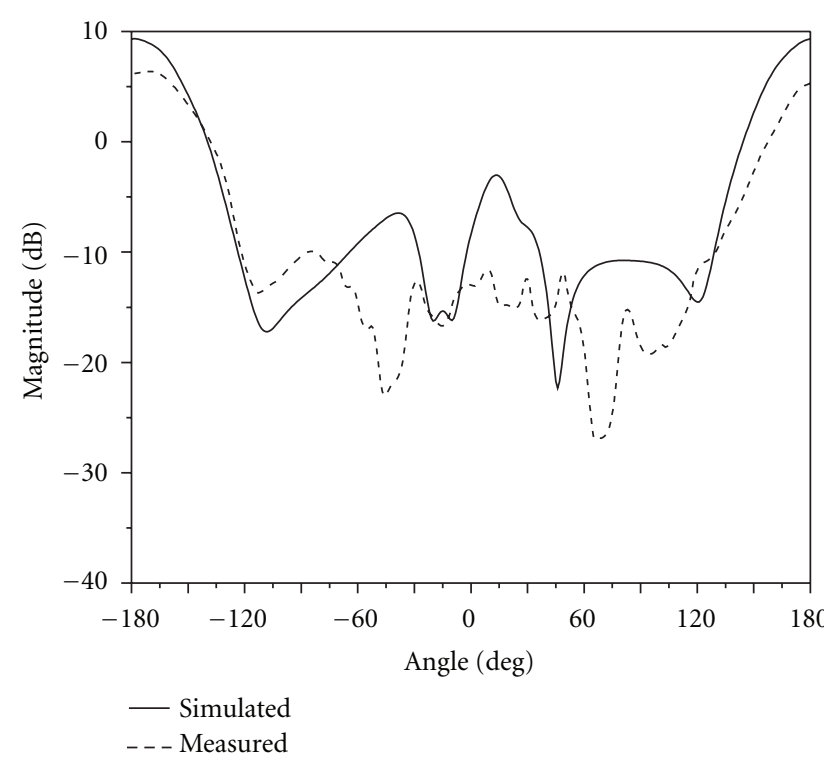

FIGURE 12: Simulated and measured $H$-plane radiation patterns reflection coefficients for $67.5^{\circ}$ phase progression.

To validate our conception, we have fabricated prototypes for $0^{\circ}, 22.5^{\circ}$, and $67.5^{\circ}$, differential phases. Measurement results, for $S 11$, are compared to simulation results and represented by Figures 4, 5, and 6 . We can see that there is a good agreement between measured and simulated data.

$E$-plane radiation patterns are shown in Figures 7 to 9 and $H$-plane radiation patterns are shown in Figures 10 to 12 , for the three differential phases. In the E-plane, a small difference in the maximum gain achieved for each differential phase between the array elements is noticed. This may be due to a little higher loss in the phase shifter portion, especially for $67.5^{\circ}$ one. However, the curves are comparable and the objective of beam scanning was achieved. In fact, for the $22.5^{\circ}$ differential phase, a scan angle of $5^{\circ}$ was achieved experimentally, while by simulation the scan angle was $6^{\circ}$, a difference of $1^{\circ}$. For $67.5^{\circ}$ differential phase, a scan angle of $18^{\circ}$ was achieved experimentally and by simulation. In the $H$-plane, we observe a gain decrease from one differential phase to another, which is in agreement with the theory. The same difference in gain between simulation and experiments can also be observed and this may be due to the same reasons as above. A photograph of the three fabricated prototypes is given in Figure 13.

\section{Conclusion}

In this paper, we studied an SIW antenna array at $10 \mathrm{GHz}$, using the phase shifter and the slot antenna designed in previous work. To do so, we designed, fabricated, and measured a two-element SIW antenna array. We proved, regarding the obtained results, that the developed SIW phase shifter and slot antenna can be combined to develop an SIW antenna array with good performances. With a $67.5^{\circ}$ differential phase between the two antenna elements, a beam scan of $18^{\circ}$

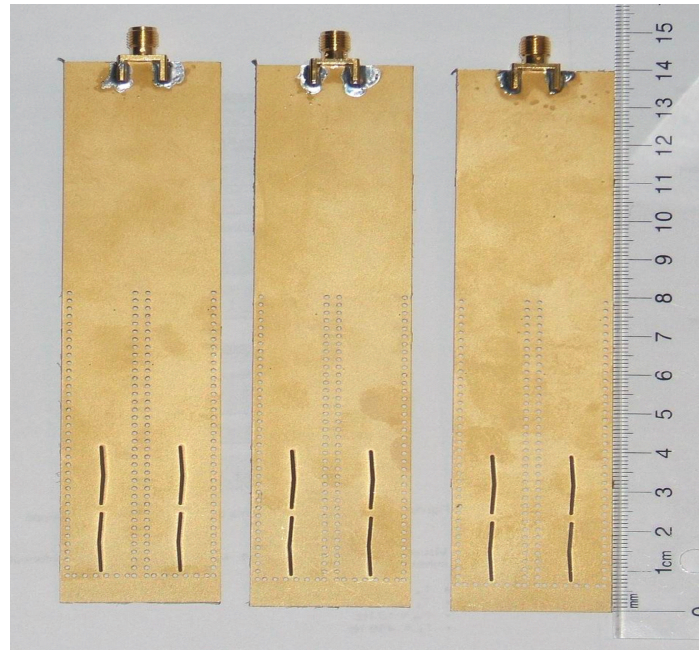

(a)

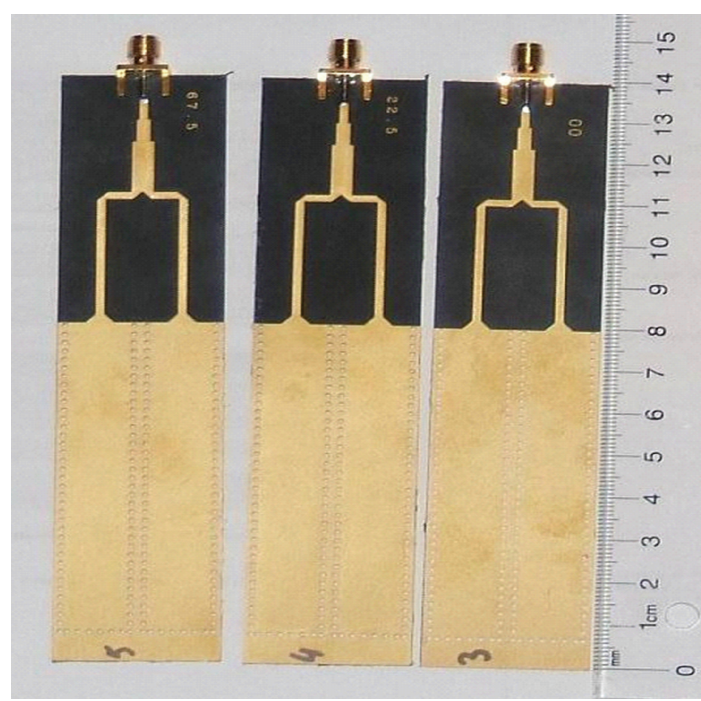

(b)

Figure 13: Photograph of the prototypes of the two-element antenna array.

was achieved. Two of our future goals are to achieve higher scan angle and improve the controllability of beam scanning.

\section{References}

[1] C. A. Balanis, Antenna Theory: Analysis and Design, Wiley and Sons, New York, NY, USA, 2nd edition, 1997.

[2] D. Deslandes and K. Wu, "Single-substrate integration technique of planar circuits and waveguide filters," IEEE Transactions on Microwave Theory and Techniques, vol. 51, no. 2 I, pp. 593-596, 2003.

[3] D. Deslandes and K. Wu, "Integrated microstrip and rectangular waveguide in planar form," IEEE Microwave and Wireless Components Letters, vol. 11, no. 2, pp. 68-70, 2001.

[4] D. Deslandes and K. Wu, "Integrated transition of coplanar to rectangular waveguides," IEEE International Microwave Symposium Digest, vol. 2, pp. 619-622, 2001. 
[5] A. J. Farrall and P. R. Young, "Integrated waveguide slot antennas," Electronics Letters, vol. 40, no. 16, pp. 974-975, 2004.

[6] L. Yan, W. Hong, G. Hua, J. Chen, K. Wu, and T. J. Cui, "Simulation and experiment on SIW slot array antennas," IEEE Microwave and Wireless Components Letters, vol. 14, no. 9, pp. 446-448, 2004.

[7] D. Stephens, P. R. Young, and I. D. Robertson, "W-band substrate integrated waveguide slot antenna," Electronics Letters, vol. 41, no. 4, pp. 165-167, 2005.

[8] B. Sanz-Izquierdo, P. R. Young, N. Grigoropoulos, J. C. Batchelor, and R. J. Langley, "Substrate-integrated folded waveguide slot antenna," in Proceedings of the IEEE International Workshop on Antenna Technology, vol. 2005, pp. 307-309, March 2005.

[9] B. Sanz-Izquierdo, P. R. Young, N. Grigoropoulos, J. C. Batchelor, and R. J. Langley, "Slot array antenna using folded waveguides," in Proceedings of the Loughborough Antennas \& Propagation Conference, UNSPECIFIED, Ed., Loughborough University, April 2005.

[10] B. Sanz Izquierdo, P. R. Young, N. Grigoropoulos, J. C. Batchelor, and R. J. Langley, "Slot antenna on C type compact substrate integrated waveguide," in Proceedings of the 35th European Microwave Conference, vol. 1, pp. 469-472, Paris, Farnce, October 2005.

[11] L. Yan, W. Hong, and K. Wu, "Simulation and experiment on substrate integrated monopulse antenna," in Proceedings of the IEEE Antennas and Propagation Society, International Symposium, vol. 1 A, pp. 528-531, July 2005.

[12] Z.-B. Weng, R. Guo, and Y.-C. Jiao, "Design and experiment on substrate integrated waveguide resonant slot array antenna at ku-band," in Proceedings of the 7th International Symposium on Antennas, Propagation and EM Theory (ISAPE '06), pp. 1-3, October 2006.

[13] W. Hong, B. Liu, G. Q. Luo et al., "Integrated microwave and millimeter wave antennas based on SIW and HMSIW technology," in Proceedings of the International Workshop on Antenna Technology: Small and Smart Antennas Metamaterials and Applications (IWAT '07), pp. 69-72, March 2007.

[14] A. Petosa, Antennas and Arrays, Course notes, Carleton University, Ottawa, Canada, 2003.

[15] K. Sellal, L. Talbi, T. A. Denidni, and J. Lebel, "Design and implementation of a substrate integrated waveguide phase shifter," IET Microwaves, Antennas and Propagation, vol. 2, no. 2, pp. 194-199, 2008.

[16] L. Talbi, K. Sellal, and T. A. Denidni, "Study of a roundended banana-shaped slot integrated antenna at X-band," in Proceedings of the IEEE International AP-S Symposium/USNCURSI Natinal Radio Science Meeting, San Diego, USA, July 2008. 

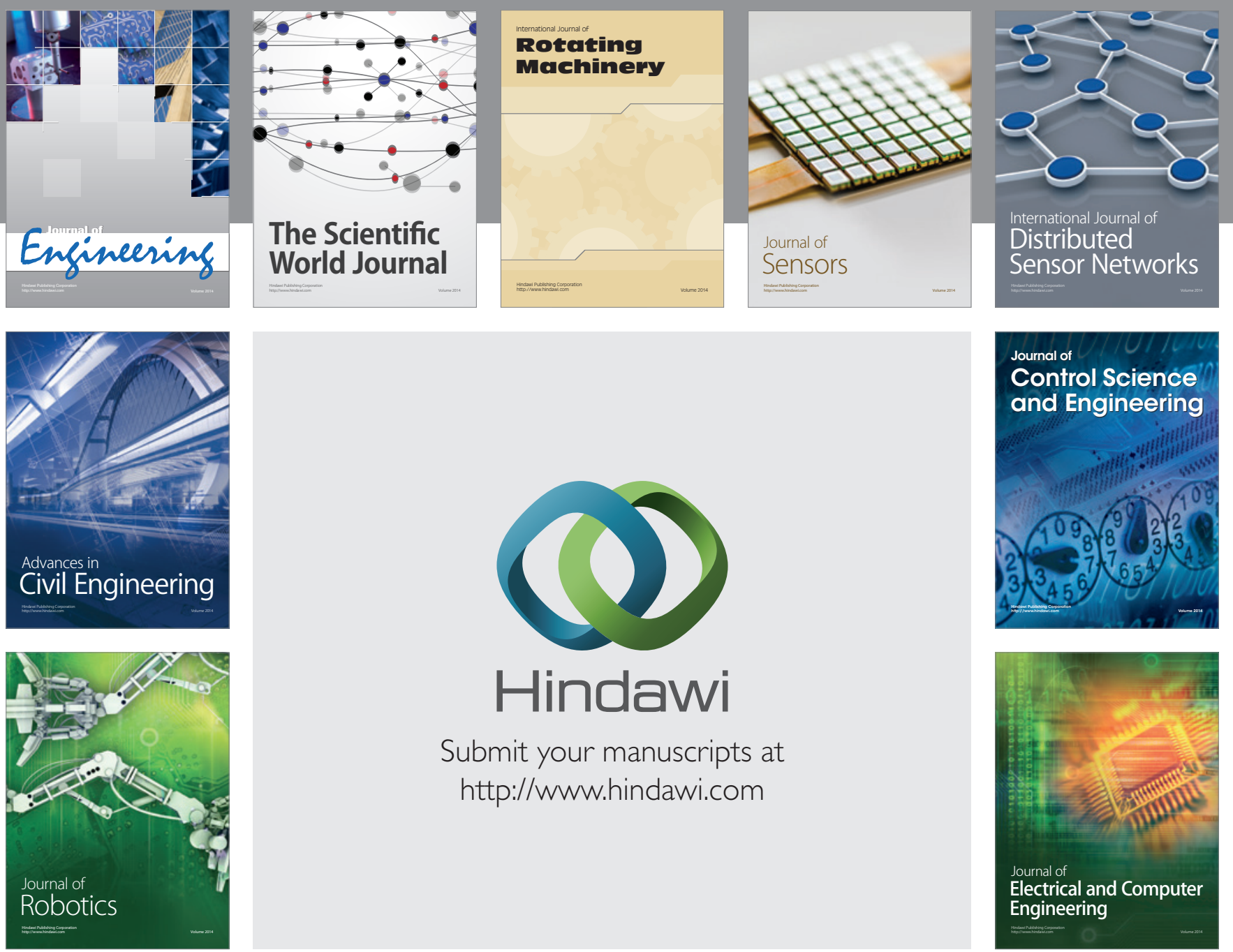

Submit your manuscripts at

http://www.hindawi.com
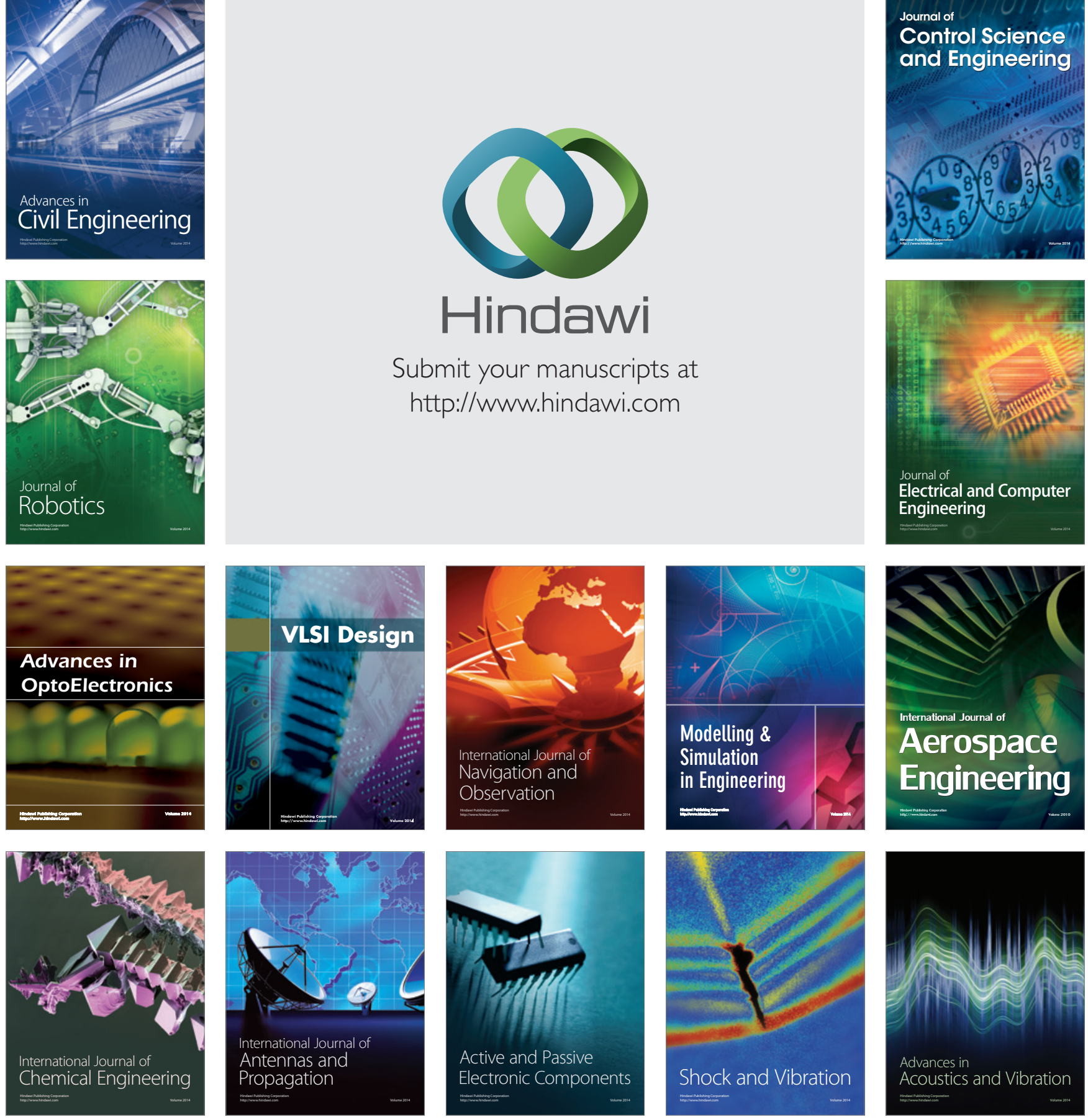